\title{
BMJ Open Measuring the preference towards patient-centred communication with the Chinese-revised Patient-Practitioner Orientation Scale: a cross-sectional study among physicians and patients in clinical settings in Shanghai, China
}

\author{
Jie Wang, ${ }^{1}$ Runyu Zou, ${ }^{1,2}$ Hua Fu, ${ }^{1}$ Haihong Qian, ${ }^{3}$ Yueren Yan, ${ }^{1,3}$ Fan Wang ${ }^{1}$
}

To cite: Wang J, Zou R, $\mathrm{Fu} \mathrm{H}$, et al. Measuring the preference towards patientcentred communication with the Chinese-revised Patient-Practitioner Orientation Scale: a cross-sectional study among physicians and patients in clinical settings in Shanghai, China. BMJ Open 2017;7:e016902. doi:10.1136/ bmjopen-2017-016902

- Prepublication history and additional material are available. To view please visit the journal online (http://dx.doi.org/10. 1136/bmjopen-2017-016902).

JW and RZ contributed equally.

Received 17 March 2017 Revised 30 June 2017 Accepted 14 July 2017

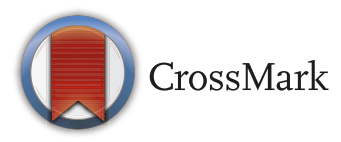

${ }^{1}$ Key Laboratory of Public Health Safety, Ministry of Education, School of Public Health, Fudan University, Shanghai, China

${ }^{2}$ Department of Child and Adolescent Psychiatry, Erasmus University Medical Center, Rotterdam, The Netherlands

${ }^{3}$ School of Basic Medical Sciences, Fudan University, Shanghai, China

Correspondence to

Dr Fan Wang;

wangfan512@126.com

\section{ABSTRACT}

Objectives To adapt the Patient-Practitioner Orientation Scale (PPOS), to a Chinese context, and explore the preference towards patient-centred communication among physicians and patients with the Chinese-revised PatientPractitioner Orientation Scale (CR-PPOS).

Design A cross-sectional questionnaire-based study. Setting Clinical settings from eight medical units, including four community hospitals and four general hospitals, in Shanghai, China.

Participants 1018 participants, including 187 physicians and 831 patients, completed this study in two successive stages.

Outcome measurements Psychometric properties of the CR-PPOS and participants' score on the CR-PPOS.

Results Compared with the original PPOS, the 11-item CR-PPOS obtained better psychometric indices. Physicians and patients scored differently on both the total CR-PPOS and its two subscales. Compared with physicians, the scores of patients were more influenced by their personal characteristics, such as age and education.

Conclusions The CR-PPOS is a better instrument in a Chinese context than the original translated version. The divergence in the extent to which patient-centred communication is preferred among Chinese physicians and patients should be noted. Adapting physicians' communication strategy to patients' preferences based on their personal characteristics can be a viable approach towards improving clinical efficiency.

\section{INTRODUCTION}

In 1969, Balint et al ${ }^{1}$ was greatly influential in the development of patient-centredness, which has been one of the most frequently discussed principles in medical practice over the past few decades. ${ }^{2}$ It has also been regarded as one of the six core components of high-quality medical care. ${ }^{3}$ Enhancing patient-centredness is seen as vital in improving the quality of healthcare delivery. ${ }^{4}$
Strengths and limitations of this study

- It is the first study to systematically assess the psychometric properties of the Patient-Practitioner Orientation Scale (PPOS) in a Chinese context.

- Preference towards patient-centred communication among Chinese physicians and patients was simultaneously measured using the Chineserevised Patient-Practitioner Orientation Scale (CRPPOS), which made it possible to make comparisons between the two groups.

- The association between broader factors and participants' preference towards patient-centred communication was explored.

- For the sake of convenience, the participants in this study were sampled only from eight clinical units in Shanghai, which might lead to limited external validity.

- Caution should be used when directly comparing scores measured by the CR-PPOS and the PPOS, as the number of items they contain are not consistent.

Patient-centredness, however, has not been uniformly defined. ${ }^{5}$ It is not clear whether patient-centredness should be considered as a set of gestures (a combination of setting, language, paralanguage and so on) or a state of mind. Furthermore, it is uncertain whether patient-centredness exists as a yearning inside the mind of the physician or the patient, whether it consists of a series of behaviours or a mindset or a compendium of things to say. ${ }^{6}$

Despite these conundrums, various conceptual models have been created to demonstrate patient-centredness for the positive effects it brings to medical care. ${ }^{78}$ Epstein et at has indicated that patient-centredness could be fulfilled at three levels: interpersonal behaviour, technical intervention and health system innovation. As a key 
element in interpersonal behaviour between physicians and patients, patient-centred communication has been a highly recommended model, enabling practitioners to offer care that is concordant with the patient's values, needs and preferences and that allows patients to become actively involved in decision that affect their health. ${ }^{1011}$ Patient-centred communication contributes to building a partnership between physicians and patients, instead of the traditional paternalism. ${ }^{12}$ Patient-centred communication has also been reported to improve a variety of clinical outcomes in diverse settings and to enhance patients' adherence to prescription medication directions and other types of treatment. ${ }^{1314}$

However, considering the cultural and contextual differences that exist in the practice of medicine, patient-centred communication may not be universally applicable despite the benefits it offers. ${ }^{15}$ Thus, it is suggested that physicians learn patients' communication preference and then incorporate them into their own communication style. ${ }^{16}$ However, available instruments for measuring the preferences in patient-centred communication remain sparse. Originally developed by Krupat et al, ${ }^{17}$ the Patient-Practitioner Orientation Scale (PPOS), which embraces the four element model of patient-centredness, has been translated into various languages and gained worldwide popularity in measuring the preferences towards patient-centred communication among physicians, medical students and patients. ${ }^{18-21}$

In China, accounts of patient-physician communication have been prominent in the new healthcare era, as patient-centredness is increasingly highlighted in clinical practice. Ting $e t a l^{22}$ conducted a survey to identify patients' preferences towards patient-centred communication in a hospital in the southwest part of China, the only known attempt to apply PPOS in China. Despite its innovativeness, there were several limitations affecting this study. For example, as an instrument introduced from abroad, PPOS' psychometric properties, such as reliability and validity, have not been well tested in the Chinese context. Second, the preference of physicians in conducting patient-centred communication has not yet been explored. Finally, for a vast country with a population in the billions, a single survey conducted in a specific medical unit can hardly be considered representative. It is thus unclear how well this instrument would work in other regions and surroundings.

We conducted this research in Shanghai, which is among the most developed cities in China and possesses abundant high-quality medical resources. Our goal was to adapt PPOS to a Chinese (Mandarin) context and assess its psychometric properties systematically. Preferences of both patients and physicians towards patient-centred communication were measured using the Chinese-revised PPOS (CR-PPOS). In addition, factors that might exert influence on physicians' and patients' preferences concerning patient-centred communication were further explored.

\section{METHODS}

\section{Description of the instrument}

Currently, PPOS has evolved into a version containing 18 items in two dimensions, Caring and Sharing. ${ }^{23}$ The nineitem Caring subscale reflects the degree to which physicians care about providing warmth and emotional support and regard the patient as a whole person. The nine-item Sharing subscale reflects the degree to which physicians believe they should share decision making information and power with the patients. ${ }^{17}$ A higher PPOS total score, as well as subscale scores, indicates a greater preference towards patient-centred style in clinical communication. Conversely, a low Caring score indicates a tendency towards a disease-centred style, while a low Sharing score indicates a tendency towards a doctor-centred style.

\section{Translation and cultural adaption}

Having obtained from the original author permission to translate and develop the PPOS in a Chinese context, scholars with academic backgrounds in medicine, public health and communication as well as the Chinese and English languages were invited to translate the PPOS into Chinese (Mandarin). Afterward, the bilingual PPOS versions were sent separately to five other advanced health practitioners for further suggestions and modifications. The Chinese PPOS (C-PPOS) was then retranslated into English and sent back to the original author for confirmation as to its accuracy.

For this C-PPOS, we strove to fit every item from the original version, except for item 17 due to noticeable culture difference. Thus, it was replaced by 'A friendly manner is a major ingredient in the doctor's treatment of the patients', which had been used in a prior study in Nepal. ${ }^{24}$ Additionally, item 2 was back-translated as "Compared with centring on individual patients in the past, focusing on the comprehensive quality of medical services nowadays is more valuable for propelling medical development', which differed from the original item, rendered as 'Although healthcare is less personal these days, this is a small price to pay for medical advances' in expression but was mostly consistent in meaning'. Finally, 12 physicians and 18 patients were enrolled in cognitive interviews to further enhance the comprehensibility of the scale in the Chinese cultural context.

\section{Pilot study design}

A pilot study was conducted in eight clinical settings in Shanghai in 2015. To reduce selection bias, four community hospitals and four general hospitals located in various areas were selected to cover a broad population. As a minimum sample size of 5-10 times the number of scale items for exploratory factor analysis (EFA) and 10-20 times for confirmatory factor analysis $(\mathrm{CFA})^{25}$ was required and allowing for a number of probable invalid responses, we included 400 interviewees. It was assumed that physicians should comprise at least $20 \%$ of the total sample. Physicians and patients were recruited using a convenient sampling approach from the outpatient 
department of each hospital. Every eligible participant was requested to complete an anonymous short questionnaire containing the C-PPOS. Retrieved questionnaires were carefully checked, and those of poor quality were removed from the dataset, including those with missing item scores or with the same item score used throughout the entire scale.

\section{Psychometric properties assessment}

In this study, we assessed the psychometric properties via reliability, validity and discriminative power tests, based on which the C-PPOS was revised to the CR-PPOS.

Internal consistency and test-retest reliability are the most widely used indicators for reliability; thus we performed both in this study. In the test-retest survey, 60 participants completed the C-PPOS again after 2-4 weeks.

We performed EFA and CFA to assess construct validity. In addition, content validity was assessed by testing the correlation of the score of each item and the score of the subscale the item belonged to, as well as the score of the total scale.

Discriminative power reflects the extent to which an item can distinguish different levels of target variables. We tested discriminative power by comparing the critical value $(\mathrm{CR})$ of each item.

\section{Formal study design}

The formal survey was launched 1 month later, in the same settings where the pilot study was conducted. As a cross-sectional study, the sample size was calculated to be 664 according to the formula provided by Raosoft, ${ }^{26}$ within a total population size of 24000000 (the estimated population of Shanghai) and a confidence level of $99 \%$. It was then expanded to 750 to guarantee sufficient valid responses. Physician and patient participants were recruited with a convenience sampling strategy. After confirming the informed consent, participants were asked to complete a questionnaire containing the CR-PPOS, general information (gender, age, education, marriage status, socioeconomic status and so on) and some other well-validated instruments, such as the Patient Confidence in Communication Scale (PCCS),${ }^{27}$ Hospital Anxiety and Depression Scale (HADS), the Rapid Health Literacy Scale ${ }^{28}$ for patients and the Maslach Burnout Inventory-General Survey (MBI-GS) and Medical Communication Competence Scale (MCCS ${ }^{29}$ for physicians.

\section{Statistical analysis}

We used Epidata V.3.1 and Excel 2007 software for dataset establishment. IBM SPSS V.20.0 and AMOS V.21.0 were employed to perform data cleaning and analysis.

Cronbach's $\alpha$ coefficient was tested as the indicator of internal consistency and reliability. Normally, a Cronbach's $\alpha$ of no less than 0.6 is deemed acceptable for an instrument with a relatively small number of items (ie, no more than 6) ${ }^{30}$ Test-retest reliability was assessed as the indicator of interclass correlation coefficient (ICC). Testretest reliability was considered poor if the ICC value was lower than 0.4 and/or the correlation was not statistically significant $(\mathrm{p}<0.05)$.

For EFA, data were subjected to a principal component analysis with extraction of eigenvalues (greater than 1) for subscales (EFA round 1) and fixed two factors for the total scale (EFA round 2). In EFA round 1, items were removed if (1) their factor loadings under either dimension were greater than $0.4,(2)$ their factor loadings under any two dimensions were close (the absolute value difference was less than 0.1 ) or (3) they were the only item under one dimension. ${ }^{31}$

CFA was performed by maximum likelihood analysis to verify the main adjustment indices of the model, including $\chi^{2} / \mathrm{df}$, root mean square error of approximation (RMSEA), goodness-of-fit index (GFI), adjusted goodness-of-fit index (AGFI), normed-fit index (NFI), incremental fit index (IFI) and comparative fit index (CFI). The recommended $\chi^{2} / \mathrm{df}$ ratio is 1 to 3 and RMSEA value $<0.08$ and GFI, AGFI, NFI, IFI and CFI $>0.9$ suggest ideal model fit. ${ }^{32}$

Respondents with the highest (top 27\%) and lowest (bottom 27\%) total scale scores were divided into two groups, after which their CR values of each item were compared to determine their discriminative power. ${ }^{33}$ The items without significantly distinct CRs were eliminated as they lacked the ability to distinguish high scores and low scores.

For single factor analysis, we performed the t-test and analysis of variance (ANOVA) for parameter testing and the Mann-Whitney $\mathrm{U}$ test for non-parameter testing. Multiple linear regression (MLR) was used in processing multifactor analysis. Only cases with complete data were included in the analysis. Statistical significance was set at $\mathrm{p}<0.05$.

\section{RESULTS}

\section{Pilot study}

\section{Participants}

Three hundred and sixty-two eligible questionnaires were included in the pilot study from 395 participants, with a valid response rate of $91.65 \%$. The mean age of the respondents was $47.41 \pm 18.42$, and approximately half of them had graduated from college (table 1).

\section{Confirmatory factor analysis of the C-PPOS}

The CFA of the C-PPOS indicated poor model fit (table 2), which called for further revision.

\section{Revision of the C-PPOS}

The Cronbach's $\alpha$ of each subscale of C-PPOS was tested as the first step of item reduction. The Cronbach's $\alpha$ of C-PPOS was 0.668, with a Caring subscale score of 0.493 and a Sharing subscale of 0.575 , showing poor internal consistent reliability. Hence, items were eliminated in a stepwise manner for each subscale separately until elimination of another item would lead to a decrease in the Cronbach's $\alpha$ of its corresponding dimension. Finally, five 


\begin{tabular}{|c|c|c|}
\hline $\begin{array}{l}\text { Demographic } \\
\text { characteristics }\end{array}$ & Physicians $(n=71)$ & Patient $(n=291)$ \\
\hline Mean age (range) & $39.39(24-64)$ & $49.43(20-96)$ \\
\hline \multicolumn{3}{|l|}{ Gender, n (\%) } \\
\hline \multirow{2}{*}{$\begin{array}{l}\text { Male } \\
\text { Female }\end{array}$} & $33(46.5 \%)$ & $123(42.3 \%)$ \\
\hline & $38(53.5 \%)$ & 165 (56.6\%) \\
\hline \multicolumn{3}{|l|}{ Education, n (\%) } \\
\hline \multirow{4}{*}{$\begin{array}{l}\text { College and above } \\
\text { Senior school } \\
\text { Junior school } \\
\text { Primary school and } \\
\text { below }\end{array}$} & 67 (94.4\%) & $112(38.5 \%)$ \\
\hline & 4 (5.6\%) & 83 (28.5\%) \\
\hline & 0 & $72(24.7 \%)$ \\
\hline & 0 & 12 (4.1\%) \\
\hline \multicolumn{3}{|l|}{ Setting, n (\%) } \\
\hline \multirow{2}{*}{$\begin{array}{l}\text { Community hospital } \\
\text { General hospital }\end{array}$} & $42(59.2 \%)$ & $130(44.7 \%)$ \\
\hline & $29(40.8 \%)$ & $161(55.3 \%)$ \\
\hline
\end{tabular}

out of nine items were retained in the Caring subscale, and eight out of nine items (except for C-PPOS9) were retained in the Sharing subscale.

In EFA, the Bartlett's sphericity test reported a $\chi^{2}$ value of $112.364(\mathrm{p}<0.001)$ for the Caring subscale and $146.846(\mathrm{p}<0.001)$ for the Sharing subscale. The KaiserMeyer-Olkin indices for the two subscales were 0.727 and 0.694 , respectively. For EFA round 1, all five of the retained items of the Caring subscale were under one principal component, which had an eigenvalue greater than 1 (2.197), explaining $43.949 \%$ of the total variance. In the Sharing subscale, C-PPOS4 and C-PPOS10 were removed as they met exclusion criteria. Afterward, EFA was performed again on the six retained items of the Sharing subscale. This time all six items grouped under one principal component (eigenvalue=2.247), which

\begin{tabular}{|c|c|c|c|}
\hline $\begin{array}{l}\text { Model fit } \\
\text { indicator }\end{array}$ & $\begin{array}{l}\text { Two factors } \\
\text { (18 items) }\end{array}$ & $\begin{array}{l}\text { Two factors } \\
\text { (11 items) }\end{array}$ & $\begin{array}{l}\text { Reference } \\
\text { value }\end{array}$ \\
\hline$\chi^{2} / \mathrm{df}$ & 5.04 & 1.85 & $<3$ \\
\hline $\mathrm{p}$ Value & $<0.001$ & $<0.001$ & $>0.05$ \\
\hline RMSEA & 0.11 & 0.06 & $<0.08$ \\
\hline GFI & 0.76 & 0.94 & $>0.90$ \\
\hline AGFI & 0.70 & 0.90 & $>0.90$ \\
\hline NFI & 0.52 & 0.81 & $>0.90$ \\
\hline IFI & 0.58 & 0.90 & $>0.90$ \\
\hline CFI & 0.57 & 0.90 & $>0.90$ \\
\hline
\end{tabular}

AGFI, adjusted goodness-of-fit index; CFA, confirmatory factor analysis; $\mathrm{CFI}$, comparative fit index; C-PPOS, Chinese PatientPractitioner Orientation Scale; CR-PPOS, Chinese-revised PatientPractitioner Orientation Scale; GFI, goodness-of-fit index; IFI, incremental fit index; NFI, normed-fit index; RMSEA, root mean square error of approximation. explained $37.448 \%$ of the total variance. Subsequently, a fixed two-factor EFA was performed to verify the construct of the merged 11-item scale. The result indicated that the five items of the Caring subscale and the six items of the Sharing subscale were well separated, explaining $41.67 \%$ of the total variance.

CFA was performed with the 11-item revised C-PPOS (CR-PPOS, see online supplementary appendix), according to the prior model, indicating a more acceptable and greatly improved model fit compared with the original scale (table 2 ).

\section{Reliability of the CR-PPOS}

The Cronbach's $\alpha$ of the entire CR-PPOS was 0.735 , with 0.709 in the Caring subscale and 0.644 in the Sharing subscale. Furthermore, the scores of the two subscales were significantly correlated to the total scale, with Spearman's coefficients of 0.744 (Caring) and 0.840 (Sharing), which were higher than those of these two subscales (0.312). The ICC was 0.787 for the CR-PPOS, 0.911 for the Caring subscale and 0.602 for the Sharing subscale. The ICC for the 11 single items ranged from 0.481 to 0.812 . The correlations were all statistically significant $(p<0.001)$, indicating satisfactory test-retest reliability.

\section{Validity of the CR-PPOS}

The construct validity was well verified through EFA and CFA (see above). As for content validity, the 11 items' scores and their corresponding subscales' scores were all significantly correlated $(\mathrm{p}<0.01)$, with Spearman's coefficients ranging from 0.452 to 0.717 .

\section{Discriminative power of the CR-PPOS}

The $\mathrm{p}$ values for CRs of the 11 items were all less than 0.01 , reaching statistically significant levels. Thus, the items retained in the CR-PPOS had good discriminative power.

\section{Formal study}

Participants

Six hundred and fifty-six eligible questionnaires out of 792 participants were retrieved in this stage, with a valid response rate of $82.83 \%$. One hundred and sixteen physicians and 540 patients were included. Respondents' demographic information is partly shown in tables 3 and 4 .

\section{Comparison of physicians' and patients' CR-PPOS scores}

The physicians received an average CR-PPOS score of $3.66 \pm 0.59$, and the patients' average score was significantly lower $(3.46 \pm 0.70)$. The physicians scored higher in Caring ( $4.71 \pm 0.82$ vs $4.08 \pm 0.95)$, while the patients scored higher in Sharing $(3.13 \pm 0.76$ vs $2.94 \pm 0.78)$. The differences were all statistically significant $(\mathrm{p}<0.05)$.

\section{Demographic characteristics and CR-PPOS scores}

The scores of physicians and patients with distinct demographic characteristics were compared, as partly listed in tables 3 and 4 . Both patients' age and education level 
Table 3 Physicians' demographic characteristics (partly) and CR-PPOS scores

\begin{tabular}{lllll}
\hline Demographic characteristics & $\begin{array}{l}\text { Number } \\
\text { (percentage) }\end{array}$ & Caring subscale & Sharing subscale & CR-PPOS total \\
\hline Gender & & & & \\
\hline Male & $43(37.1 \%)$ & $4.75 \pm 0.95$ & $2.81 \pm 0.79$ & $3.62 \pm 0.62$ \\
\hline Female & $73(62.9 \%)$ & $4.68 \pm 0.74$ & $3.01 \pm 0.77$ & $3.68 \pm 0.57$ \\
\hline p Value & & 0.666 & 0.166 & 0.648 \\
\hline Age (Group) & & & \\
\hline-35 & $50(43.1 \%)$ & $4.78 \pm 0.96$ & $2.89 \pm 0.71$ & $3.69 \pm 0.61$ \\
\hline 50 & $52(44.8 \%)$ & $4.69 \pm 0.63$ & $2.92 \pm 0.85$ & $3.63 \pm 0.52$ \\
\hline $51-$ & $10(8.7 \%)$ & $4.74 \pm 0.36$ & $3.33 \pm 0.66$ & $3.90 \pm 0.41$ \\
\hline p Value & & 0.827 & 0.247 & 0.363 \\
\hline Education & & & \\
\hline Senior school or below & $2(1.7 \%)$ & $4.20 \pm 0.00$ & $3.00 \pm 0.17$ & $3.41 \pm 0.14$ \\
\hline College & $71(61.2 \%)$ & $4.69 \pm 0.87$ & $3.04 \pm 0.76$ & $3.69 \pm 0.64$ \\
\hline Postgraduate & $42(36.2 \%)$ & $4.78 \pm 0.75$ & $2.75 \pm 0.80$ & $3.61 \pm 0.51$ \\
\hline p Value & & 0.572 & 0.161 & 0.672 \\
\hline Marriage status & & & \\
\hline Married & $89(76.7 \%)$ & $4.69 \pm 0.76$ & $2.91 \pm 0.77$ & $3.64 \pm 0.53$ \\
\hline Unmarried & $26(22.4 \%)$ & $4.88 \pm 0.82$ & $3.08 \pm 0.74$ & $3.82 \pm 0.61$ \\
\hline p Value & & 0.270 & 0.318 & 0.149 \\
\hline
\end{tabular}

${ }^{*} \mathrm{p}<0.05$.

CR-PPOS, Chinese-revised Patient-Practitioner Orientation Scale.

were significantly associated with their scores on the Caring subscale $(\mathrm{p}<0.05)$, the

Sharing subscale $(\mathrm{p}<0.001)$ and the total CR-PPOS $(\mathrm{p}<0.01)$. Patients' income was only significantly associated with the Caring subscale score $(\mathrm{p}<0.05)$ and the total CR-PPOS score $(\mathrm{p}<0.01)$. Furthermore, patients' experience as medical staff was likely to improve their scores on the Sharing subscale $(\mathrm{p}<0.05)$ and the total CR-PPOS $(\mathrm{p}<0.05)$. However, no associations of such were found among physicians.

\section{Physicians' burnout and CR-PPOS scores}

The burnout level of physicians was measured by the MBI-GS. According to the data, the group of 'relatively severe' (scoring 3-5) and the group of 'extremely severe' (scoring 5 or above) were merged as a 'severe' group (scoring 3 or above), compared with the 'light' group (scoring 3 or below). Physicians who reported 'severe' burnout scored significantly lower in both the Caring subscale and the total scale than those reporting 'light' burnout.

\section{Physicians' medical communication competency and CR- PPOS scores}

Ninety-nine percent of physicians completed the MCCS, which was used to assess the medical communication competency of both physicians and patients. Although physicians were normally assessed by their patients using MCCS, we transformed this into a self-reported scale for physicians in this study. The results indicated that, although the scores of the four dimensions of MCCS were related, no correlation was found between the MCCS scores and the CR-PPOS scores as well as its subscales.

\section{Patients' anxiety and depression and CR-PPOS scores}

Five hundred and two patients finished the HADS, an instrument for rapidly screening anxiety and depressive symptoms among clinic physicians and patients. With the cut-off point of 11, 309 patients $(57.2 \%)$ were determined to be anxiety-positive, and $277(51.3 \%)$ were determined as depression-positive. Meanwhile, it should be noticed that HADS can only be used for screening purposes, ${ }^{34}$ so the positive results cannot be equal to the anxiety/ depression with clinical significance.

As anxiety and depressive symptoms were highly comorbid,$^{35}$ a two-way ANOVA was performed as the first stage to explore whether an interaction effect existed. It turned out that there was no interaction effect between anxiety and depression. Anxiety was found to lead to a decrease in patients' scores on both the Caring subscale $(\mathrm{p}<0.01)$ and the total CR-PPOS $(\mathrm{p}<0.05)$. However, patients' scores on neither the total scale nor the subscales seemed to be influenced by their depressive symptoms.

\section{Patients' health literacy, PCCS and CR-PPOS scores}

Using the three-item Rapid Health Literacy Scale, no statistical difference was found in the total CR-PPOS score and the two subscale scores between the poor literacy group 
Table 4 Patients' demographic characteristics (partly) and CR-PPOS scores

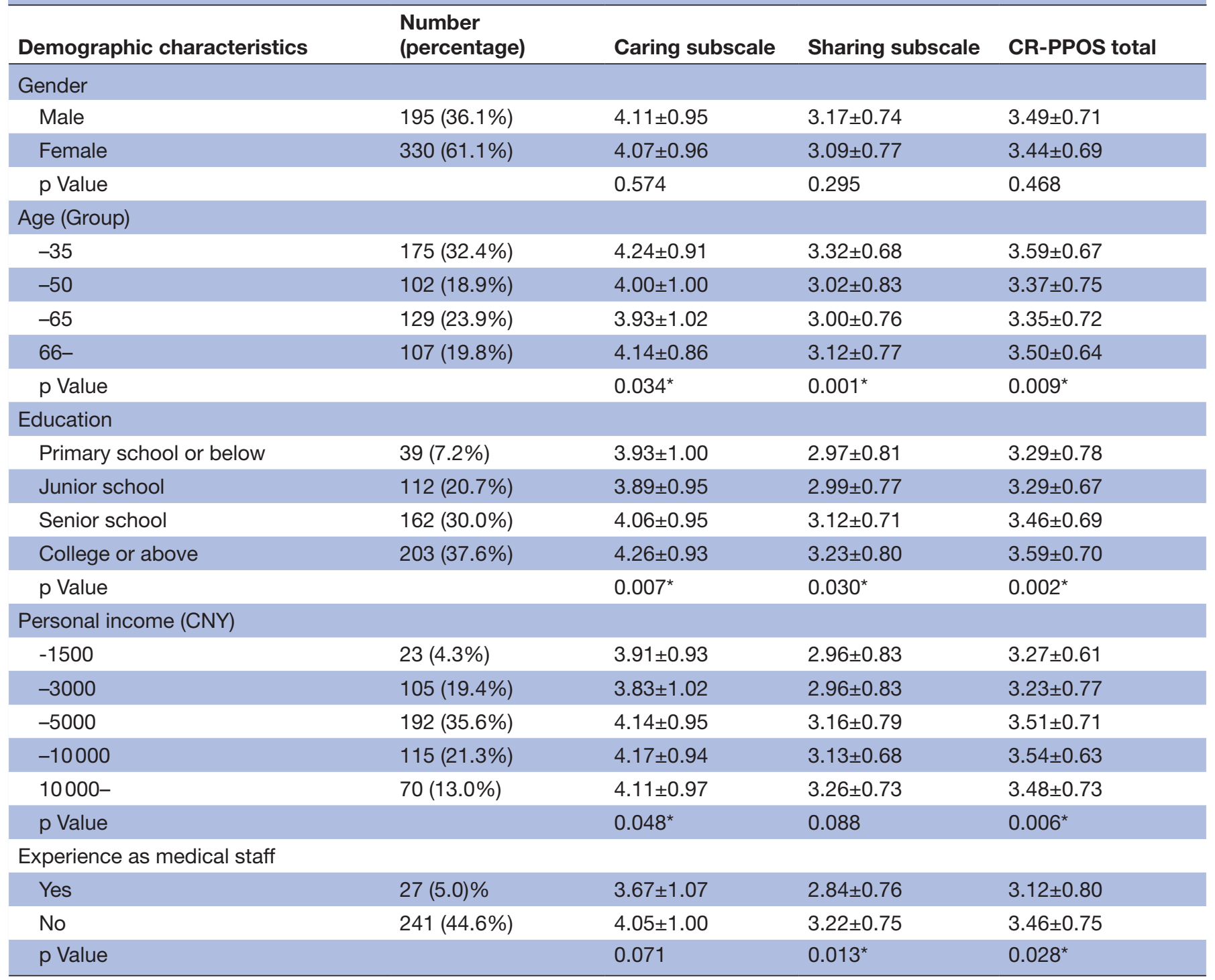

${ }^{*} \mathrm{p}<0.05$.

CR-PPOS, Chinese-revised Patient-Practitioner Orientation Scale; CNY, Chinese Yuan.

and the adequate literacy group, while patients' health literacy scores showed a significantly positive correlation with their Sharing subscale scores $\left(\mathrm{r}_{\mathrm{s}}=0.112, \mathrm{p}=0.011\right)$. Similarly, patients' confidence in medical communication, as measured by PCCS was inversely correlated with their scores on the Sharing subscale $\left(r_{\mathrm{s}}=-0.261, \mathrm{p}<0.001\right)$. In the following partial correlation tests, the correlation between PCCS and the Sharing subscale score remained significant after controlling for the health literacy score $\left(r_{s}=-0.232, p<0.001\right)$, while no correlation existed between the health literacy score and the Sharing subscale score after controlling for PCCS.

\section{Multivariable analysis}

After testing the feasibility, MLR showed that the total burnout level might be an influential factor for the physicians in Caring and total CR-PPOS scores, and more factors were associated with the CR-PPOS scores of the patients (table 5).

\section{DISCUSSION}

Although the PPOS has been widely used in various languages, only a few studies have systematically tested its psychometric property, ${ }^{36-38}$ and no related results have been reported in China to date. This study showed that neither the ICC of the overall 18-item C-PPOS nor its two subscales were above 0.7 , which was comparable to the existing research. Deletion of items 9 and 17 improved the Cronbach's $\alpha$, which is consistent with a study conducted in Sri Lanka ${ }^{39}$ After modification, the two subscales of the 11-item PPOS were well separated in a fixed-factor EFA, with better indexes than prior similar studies, and 


\begin{tabular}{|c|c|c|c|c|}
\hline Dimension & Variables & B & $95 \% \mathrm{Cl}$ & p Value \\
\hline \multicolumn{5}{|l|}{ Physicians } \\
\hline Sharing subscale & - & - & - & - \\
\hline CR-PPOS total & Total burnout & -0.341 & $(-0.611$ to -0.071$)$ & 0.014 \\
\hline \multirow[t]{3}{*}{ Caring subscale } & Age (Group) & -0.292 & $(-0.499$ to -0.086$)$ & 0.006 \\
\hline & Education & 0.251 & (0.079 to 0.423$)$ & 0.005 \\
\hline & Experience as medical staff & 0.538 & (0.046 to 1.029$)$ & 0.032 \\
\hline \multirow[t]{2}{*}{ Sharing subscale } & Age (Group) & -0.202 & $(-0.361$ to -0.043$)$ & 0.013 \\
\hline & Education & 0.169 & (0.039 to 0.299$)$ & 0.011 \\
\hline \multirow[t]{3}{*}{ CR-PPOS total } & Age (Group) & -0.242 & $(-0.396$ to -0.087$)$ & 0.002 \\
\hline & Education & 0.222 & (0.093 to 0.350$)$ & 0.001 \\
\hline & Experience as medical staff & 0.521 & (0.154 to 0.887$)$ & 0.006 \\
\hline
\end{tabular}

CR-PPOS, Chinese-revised Patient-Practitioner Orientation Scale.

the overall scale validity was reconfirmed by CFA. Taking into account the test-retest reliability and discriminative power, the 11-item CR-PPOS obtained better psychometric property than the original 18 -item scale. Thus, the CR-PPOS is considered to have greater applicability in the Chinese context.

Using the 11-item CR-PPOS, physicians and patients indicated similar trends in the achieved scores. In the overall scale, they both obtained medium scores (around the median value of 3.5), and both had relatively high Caring scores (over 4.0) and low Sharing scores (around 3.0 or below). This indicated that, although physicians and patients generally showed a medium level of patient-centredness in clinical communication, they expressed higher preferences towards caring from a biopsychosocial perspective than shared information and involvement in decision making. Although the physicians' data are still absent in China, the $95 \%$ CI of the mean score of patients in this study slightly overlapped with that of the prior study, ${ }^{22}$ which implied that Chinese patients might express similar preferences towards patient-centred communication, regardless of the regions they were living in. The differences between the scores of physicians and patients, however, may still prompt the gap in Chinese physicians and patients regarding their understanding and expectations in clinical communication. Comparing the data of this study with that from abroad, the majority showed a similar pattern that physicians were more patient-centred in Caring than in Sharing, but there were still two exceptions; the surveys conducted in Portugal and Australia indicated opposite results, ${ }^{40}{ }^{41}$ which may be due to the difference in physician training modes and local health systems. Thus, further research is needed to determine the reasons for such a distinction.

Preference towards patient-centred communication, as measured by the PPOS, has been reported to be influenced by both personal characteristics and social environmental factors. This study represents the first attempt to detect the potential influential factors of patient-centred communication among Chinese physicians. The results showed no association between the CR-PPOS scores and physicians' gender, age, education level, career length or type of setting. These results were consistent with several prior studies in other countries, though female physicians were found to score significantly higher than their male colleagues in some studies. ${ }^{42}{ }^{43}$ Apart from these factors, which were frequently mentioned in the existing research, we found that burnout level might exert impact on physicians' PPOS total score as well as their Caring subscale score, indicating that physicians with a higher total burnout level were generally less likely to be patient-centred in clinical communication. Although we assumed that poor communication ability might relate to a lower preference for patient-centredness in communication, no link was found between physicians' medical communication competency, as measured by MCCS and their PPOS scores in this study.

As Ting et $a l^{22}$ reported, age and education mainly influenced Chinese patients' overall preference on patient-centred communication. In this study, younger and/or better-educated patients also expressed a higher preference for patient-centred communication in both the Caring and Sharing dimensions. Although some studies have reported a gender difference, ${ }^{36394445}$ it 
seemed that for Chinese patients, age and education level, rather than gender, contribute to the different preferences towards patient-centred communication. Meanwhile, the type of setting and socioeconomic status are not considered as influential factors, which was controversial. ${ }^{46}$ One interesting find was that possessing experience as medical staff decreased the extent to which patients wanted a patient-centred communication style. A plausible explanation is that those who had worked as medical staff had obtained a more comprehensive understanding of how hospitals function than those who had not. Thus, they subconsciously lowered their expectation of a patient-centred manner in communication, which might raise the demand for physicians, due to their sympathy towards the physicians for their heavy workload. Further, although anxiety seemed to be influential in single factor analysis, the association between the CR-PPOS score and anxiety disappeared in the multivariable analysis, implying that anxiety was more likely to be a confounder. Meanwhile, there is a need to further probe the role of patient communication confidence as well as its seeming mediation effect on the relationship between patients' health literacy and preference for shared information and decision making.

The main limitation of this study lies in that, due to feasibility considerations, the participants were only recruited from a limited number of medical units, and a convenient sampling strategy was adopted. Hence, though we have made some efforts to reduce it, selection bias might still be a major issue, which could influence the external validity of the findings in this study. Namely, although the CR-PPOS itself can be well generalised to other studies aiming at a Chinese-speaking population, the extent to which patient-centred communication is preferred and how it is influenced can be different. Another point to be noticed is, as the CR-PPOS was developed from the PPOS following a standardised statistical process, without any extra items being added to keep the numbers of items constant, it may be inappropriate to directly compare the scores measured by the CR-PPOS and the PPOS.

Considering the deteriorating physician-patient relationships in current Chinese society, this study has significant implications for medical practice. With the valid instrument CR-PPOS, on one hand, the divergence in communication preference between physicians and patients can be discovered. On the other hand, it will be possible and reasonable to link certain personal characteristics with individuals' preference towards clinical communication, and in China that is particularly true for patients according to this study. Based on these findings, specific training can be developed and offered to physicians, guiding them on how to recognise patients with different communication preferences and to adopt corresponding communication strategies afterwards. In this way, patients' expectations are better fulfilled and communication efficiency is also enhanced, both contributing to reduced complaints in clinical communication and improved physician-patient relationships. ${ }^{47}$

\section{CONCLUSION}

The CR-PPOS was developed as an applicable instrument to measure the preference towards patient-centred communication of physicians and patients in a Chinese context. Physicians and patients were generally more patient-centred in medical communication regarding overall biopsychosocial care than with respect to shared information and decision making, but there were still significant gaps between physicians and patients in the extent to which they prefer this type of communication. Relieving burnout could help physicians to be more patient-centred in communication. Patients of a young age, high education level and without medical staff experience tended to have a higher preference towards patient-centred communication.

Acknowledgements We appreciate Professor Edward Krupat of Harvard University for his generous authorisation to use and revise the PPOS for the Chinese context. We are also grateful to the coordinators of the collaborating hospitals for their kind assistance.

Contributors JW granted research funding, engaged in study design and data analysis and was the main drafter of the Introduction and Discussion sections. RZ led study design, data collection, data analysis and drafted the Method and Results sections of the manuscript. HF and FW were the co-principal investigators of this project, granting research funding and mentoring study design, data collection and article revision. They also issued final approval for submission. $\mathrm{HQ}$ and $\mathrm{YY}$ contributed to data collection and refining the article. All authors have approved the final version of this manuscript.

Funding This work was supported by the first-class (General Financial Grant from the China Postdoctoral Science Foundation) grant number (2015M580283) and (Construction of the key disciplines of the fourth round public health three-year action plan of Shanghai Health and Family Planning Commission) grant number (15GWZK1001).

Competing interests JW had financial support from the China Postdoctoral Science Foundation for the submitted work, FW has received funds from Shanghai Health and Family Planning Commission; no financial relationships with any organisations that might have an interest in the submitted work in the previous three years; no other relationships or activities that could appear to have influenced the submitted work.

Patient consent Detail has been removed from this case description/these case descriptions to ensure anonymity. The editors and reviewers have seen the detailed information available and are satisfied that the information backs up the case the authors are making.

Ethics approval The study was approved by Fudan University School of Public Health Institutional Review Board (No. IRB\#2015-12-0575).

Provenance and peer review Not commissioned; externally peer reviewed.

Data sharing statement Additional data from this study could be accessed by contacting the corresponding author Fan Wang via wangfan512@126.com.

Open Access This is an Open Access article distributed in accordance with the Creative Commons Attribution Non Commercial (CC BY-NC 4.0) license, which permits others to distribute, remix, adapt, build upon this work non-commercially, and license their derivative works on different terms, provided the original work is properly cited and the use is non-commercial. See: http://creativecommons.org/ licenses/by-nc/4.0/

(c) Article author(s) (or their employer(s) unless otherwise stated in the text of the article) 2017. All rights reserved. No commercial use is permitted unless otherwise expressly granted.

\section{REFERENCES}

1. Balint M, Ball DH, Hare ML. Training medical students in patientcentered medicine. Compr Psychiatry 1969;10:249-58.

2. Ishikawa $\mathrm{H}$, Hashimoto $\mathrm{H}$, Kiuchi $\mathrm{T}$. The evolving concept of "patientcenteredness" in patient-physician communication research. Soc Sci Med 2013;96:147-53. 
3. Institute of Medicine. Crossing the quality chasm: a new health system for the 21st century. Washington (DC): National Academies Press, 2001:39-40.

4. Aljuaid M, Mannan F, Chaudhry Z, et al. Quality of care in university hospitals in Saudi Arabia: a systematic review. BMJ Open 2016;6:e008988.

5. Castro EM, Van Regenmortel T, Vanhaecht K, et al. Patient empowerment, patient participation and patient-centeredness in hospital care: a concept analysis based on a literature review. Patient Educ Couns 2016;99:1923-39.

6. Skelton J. Language and clinical communication: this bright Babylon Oxford: Radcliffe Publishing, 2008:93-8.

7. Stewart M, Brown JB, Weston WW, et al. Patient-centered medicine: transforming the clinical method. 2nd edn. United Kinddom: Radcliffe Medical Press, 2003:5-16.

8. Hudon C, Fortin M, Haggerty JL, et al. Measuring patients' perceptions of patient-centered care: a systematic review of tools for family medicine. Ann Fam Med 2011;9:155-64.

9. Epstein RM, Franks P, Fiscella K, et al. Measuring patient-centered communication in patient-physician consultations: theoretical and practical issues. Soc Sci Med 2005;61:1516-28.

10. Bensing JM, Verhaak PF, van Dulmen AM, et al. Communication: the royal pathway to patient-centered medicine. Patient Educ Couns 2000;39:1-3

11. Mead N, Bower P. Patient-centredness: a conceptual framework and review of the empirical literature. Soc Sci Med 2000;51:1087-110.

12. Taylor K. Paternalism, participation and partnership - the evolution of patient centeredness in the consultation. Patient Educ Couns 2009;74:150-5

13. Greenfield S, Kaplan SH, Ware JE, et al. Patients' participation in medical care. J Gen Intern Med 1988;3:448-57.

14. Marinker M. From compliance to concordance: achieving shared goals in medicine taking. Brit Med J 1997;314:747-8.

15. Schiavo R. Health communication: from theory to practice. 2 nd edn. San Francisco: Jossay-Bass, 2013:195-6.

16. Morris MA, Clayman ML, Peters KJ, et al. Patient-centered communication strategies for patients with aphasia: discrepancies between what patients want and what physicians do. Disabil Health $\mathrm{J}$ 2015;8:208-15.

17. Krupat E, Hiam CM, Fleming MZ, et al. Patient-centeredness and its correlates among first year medical students. Int J Psychiatry Med 1999;29:347-56.

18. Kim MJ. Differences in attitude toward patient-centeredness in patients and physicians. Korean J Med Educ 2013;25:149-56.

19. Ishikawa $\mathrm{H}$, Eto $\mathrm{M}$, Kitamura K, et al. Resident physicians' attitudes and confidence in communicating with patients: a pilot study at a Japanese university hospital. Patient Educ Couns 2014;96:361-6.

20. Tsimtsiou Z, Kirana PS, Hatzichristou D. Determinants of patients attitudes toward patient-centered care: a cross-sectional study in Greece. Patient Educ Couns 2014;97:391-5

21. Dockens AL, Bellon-Harn ML, Manchaiah V. Preferences to patientcenteredness in pre-service speech and hearing sciences students: a cross-sectional study. J Audiol Otol 2016;20:73-9.

22. Ting X, Yong B, Yin L, et al. Patient perception and the barriers to practicing patient-centered communication: a survey and in-depth interview of Chinese patients and physicians. Patient Educ Couns 2016;99:364-9.

23. Krupat E, Rosenkranz SL, Yeager CM, et al. The practice orientations of physicians and patients: the effect of doctor-patient congruence on satisfaction. Patient Educ Couns 2000;39:49-59.

24. Moore M. What does patient-centred communication mean in Nepal? Med Educ 2008;42:18-26.

25. Hair JF, Black WC, Babin BJ, et al. Multivariate Data analysis. 7th edn. Beijing: China Machine Press, 2011:100-23.
26. Raosoft Inc. Sample size calculation [online]. www.raosoft.com/ samplesize.html.

27. Tran AN, Haidet P, Street RL, et al. Empowering communication: a community-based intervention for patients. Patient Educ Couns 2004;52:113-21.

28. Chew LD, Bradley KA, Boyko EJ. Brief questions to identify patients with inadequate health literacy. Fam Med 2004;36:588-94.

29. Cegala DJ, Coleman MT, Turner JW. The development and partial assessment of the medical communication competence scale. Health Commun 1998;10:261-88.

30. Ponterotto JG, Ruckdeschel DE. An overview of coefficient alpha and a reliability matrix for estimating adequacy of internal consistency coefficients with psychological research measures. Percept Mot Skills 2007;105:997-1014.

31. Osborne JW, Costello AB. Best practices in exploratory factor analysis: four recommendations for getting the most from your analysis. Pract Assess Res Eval 2005;10:1-9.

32. Brown TA. Confirmatory factor analysis for applied research. 2nd edn. New York: The Guilford Press, 2015:67-73.

33. Backhoff E, Larrazolo N, Rosas M. The level of difficulty and discrimination power of basic knowledge and skill examination (EXHCOBA). Revista Electrónica de Investigación Educativa 20002016;2:1-16.

34. Snaith RP. The hospital anxiety and depression scale. Health Qual Life Outcomes 2003;1:29.

35. Wu Z, Fang Y. Comorbidity of depressive and anxiety disorders: challenges in diagnosis and assessment. Shanghai Arch Psychiatry 2014;26:227-31.

36. Krupat E, Yeager CM, Putnam S. Patient role orientations, doctorpatient fit, and visit satisfaction. Psychol Health 2000;15:707-19.

37. Pereira CM, Amaral CF, Ribeiro MM, et al. Cross-cultural validation of the Patient-Practitioner Orientation Scale (PPOS). Patient Educ Couns 2013;91:37-43

38. Kiessling C, Fabry G, Rudolf Fisher M, et al. German translation and construct validation of the Patient-Provider Orientation Scale(PPOS-D12). Psychother Psychsom Med Psychol 2014:64:122-7.

39. Mudiyanse RM, Pallegama RW, Jayalath T, et al. Translation and validation of patient-practitioner orientation scale in Sri Lanka. Educ Health 2015;28:35-40.

40. Laplante-Lévesque A, Hickson L, Grenness C. An Australian survey of audiologists' preferences for patient-centredness. Int J Audiol 2014;53:S76-S82.

41. Manchaiah V, Gomersall PA, Tomé D, et al. Audiologists' preferences for patient-centredness: a cross-sectional questionnaire study of cross-cultural differences and similarities among professionals in Portugal, India and Iran. BMJ Open 2014;4:e005915.

42. Abiola T, Udofia O, Abdullahi AT. Patient-doctor relationship: the practice orientation of doctors in Kano. Niger J Clin Pract 2014;17:241-7.

43. Mann KJ, Hoffman A, Miller D, et al. The effect of a patient- and family-centered care curriculum on pediatrics residents' patientcenteredness. J Grad Med Educ 2013;5:36-40.

44. Krupat E, Hsu J, Irish J, et al. Matching patients and practitioners based on beliefs about care: results of a randomized controlled trial. Am J Manag Care 2004:10:814-22.

45. Lau SR, Christensen ST, Andreasen JT. Patients' preferences for patient-centered communication: a survey from an outpatient department in rural sierra leone. Patient Educ Couns 2013;93:312-8.

46. Little P, Everitt H, Williamson I, et al. Preferences of patients for patient centred approach to consultation in primary care: observational study. BMJ 2001;322:468-72.

47. Liu X, Rohrer W, Luo A, et al. Doctor-patient communication skills training in mainland China: a systematic review of the literature. Patient Educ Couns 2015;98:3-14. 